\title{
Physicochemical, Thermomechanical, and Swelling Properties of Radiation Vulcanised Natural Rubber Latex Film: Effect of Diospyros peregrina Fruit Extracts
}

\author{
Kazi Md Zakir Hossain, ${ }^{1,2}$ Nashid Sharif, ${ }^{2}$ N. C. Dafader, ${ }^{3}$ \\ M. E. Haque, ${ }^{3}$ and A. M. Sarwaruddin Chowdhury ${ }^{4}$ \\ ${ }^{1}$ Division of Materials, Mechanics and Structures, Faculty of Engineering, University of Nottingham, Nottingham, NG7 2RD, UK \\ ${ }^{2}$ Faculty of Science and Information Technology, Daffodil International University, Dhaka 1207, Bangladesh \\ ${ }^{3}$ Nuclear and Radiation Chemistry Division, Institute of Nuclear Science \& Technology, Bangladesh Atomic Energy Commission, \\ Dhaka 1000, Bangladesh \\ ${ }^{4}$ Department of Applied Chemistry and Chemical Engineering, University of Dhaka, Dhaka 1000, Bangladesh
}

Correspondence should be addressed to Kazi Md Zakir Hossain; hossain015@yahoo.com

Received 23 March 2013; Accepted 22 April 2013

Academic Editors: T. R. Chantara, W. S. Chow, X. Colin, A. V. Raghu, and J. I. Velasco

Copyright (C) 2013 Kazi Md Zakir Hossain et al. This is an open access article distributed under the Creative Commons Attribution License, which permits unrestricted use, distribution, and reproduction in any medium, provided the original work is properly cited.

A range of radiation vulcanised natural rubber latex (RVNRL) films were prepared using various concentrations of aqueous extracts of mature Diospyros peregrina fruit, which acted as a cross-linking agent. The surface of the RVNRL films exhibited an aggregated morphology of the rubber hydrocarbon with increasing roughness due to increasing fruit extract contents in the latex. An improvement in tensile strength, tensile modulus, and storage modulus of RVNRL films was observed with the addition of fruit extracts compared to the control film due to their cross-linking effect. The glass transition $\left(T_{g}\right)$ temperature of all the RVNRL films was found to be at around $-61.5^{\circ} \mathrm{C}$. The films were also observed to be thermally stable up to $325^{\circ} \mathrm{C}$, while the maximum decomposition temperature appeared at around $375^{\circ} \mathrm{C}$. The incorporation of fruit extracts further revealed a significant influence on increasing the crystallinity, gel content, and physical cross-link density of the RVNRL films.

\section{Introduction}

Virgin natural polymers like rubber latex, an elastic macromolecular polymer (polyisoprene), have inherently low mechanical and thermal stability properties. Natural rubber is highly sensitive to thermal decomposition and autooxidation and, therefore, undergoes thermal aging when exposed to heat, air, and ozone resulting in poor mechanical, thermal, and swelling properties. In order to improve their mechanical properties the rubber molecules are being processed with different types of antioxidants and particulate fillers, such as silica [1,2], clays [3], carbon black [4], and carbon nanotubes $[5,6]$ to expand their applications in various fields. Radiation vulcanisation is also being employed to improve the mechanical properties of natural rubber $[5,7$, 8]. Some nonwater soluble amino acids, such as cystine, asparagines, and alanine, were also used as antioxidant in radiation vulcanised natural rubber latex (RVNRL) films and showed good antiaging effect on RVNRL films with tensile strength retentions ranging from $70 \%$ to $80 \%$ after accelerated aging at $100^{\circ} \mathrm{C}$ for $24 \mathrm{~h}$ compared to RVNRL film containing no antioxidant (tensile strength retention $~ 35 \%$ ) [9]. They also reported Keratin from chicken feather as a potential antioxidant (tensile strength retention $\sim 60 \%$ ) for RVNRL film. Tris(nonylated phenyl)phosphite (TNP) [10$12]$, polyfuran, polythiophene [13], polyamines [3, 14], and pyridazine derivatives [15] were also reported to be effective antioxidants to prolong the life of natural and synthetic rubber films.

Košíková et al. [16] investigated sulphur free lignin (10$30 \mathrm{phr}$ ) as a natural filler in natural rubber which significantly improved the tensile properties of the films. For 
example, tensile strength of $\sim 3.99 \mathrm{MPa}$ was reported for the rubber film containing 10 parts per hundred rubber (phr) lignins compared to the control rubber film with no lignin content $(\sim 1.87 \mathrm{MPa})$. In another study, carbon black filled natural rubber containing lignin was suggested to have positive stabilising effect after thermooxidative aging of rubber films at $80^{\circ} \mathrm{C}$, which was comparable to the conventional synthetic antioxidant ( $N$-phenyl- $N$-isopropylp-phenylenediamine (IPPD)) [17]. Rodrigues et al. [18] investigated the Cashew Nut Shell Liquid (CNSL) as a natural antioxidant in cis-1,4-polyisoprene rubber and showed that addition of 5\% CNSL had the highest antioxidant activity over the thermal oxidation at $140^{\circ} \mathrm{C}$ of polyisoprene rubber.

The Diospyros peregrina fruit belongs to the Ebenaceae family locally called River ebony, Gaub, and/or Indian persimmon. The extremely slimy pulp comes out of the fruit as gum exudates which mainly contained triterpenes, alkenes, flavonoids, and tannins [19-22] and had already showed its antioxidant [23], antidiabetic [24, 25], antidiarrhoea, and antidysentery properties [26]. The aqueous extracts of Diospyros peregrina fruit have been used in the radiation vulcanised (from 0 to $20 \mathrm{kGy}$ ) natural rubber latex films as a natural antioxidant to evaluate the mechanical properties after thermal aging at $100^{\circ} \mathrm{C}$ for $24 \mathrm{~h}$ [23]. Addition of $10 \mathrm{phr}$ natural antioxidant at $15 \mathrm{kGy}$ absorbed dose was reported to be optimum for the significant improvement of tensile strength and tear resistance properties of RVNRL films.

Recently improvement of the materials properties of natural rubber has also been reported via grafting and/or blending with different types of polymers, such as styrenebutadiene rubber [27], acrylamide [28], polypropylene, [29], and chitosan [30]. The aim of the present study was to investigate the influence of gummy Diospyros peregrina fruit extracts as a natural cross-linking agent on the mechanical, thermomechanical, thermal, crystallization, and swelling properties of RVNRL films. The morphological, surface roughness, gel content, and physical cross-link density properties of the rubber films with various fruit extract contents were also investigated.

\section{Experimental}

2.1. Processing of RVNRL Films. The field latex was collected from the Atomic Energy Research Establishment (AERE) rubber garden, Savar, Bangladesh, and immediately preserved with ammonia solution (BDH, UK). A laboratory scale centrifuge machine (SPL-100, Saito Separator Ltd., Japan) was employed to concentrate the latex to $60 \%$ total solids content (TSC), followed by dilution with ammonia solution $(1.5 \% \mathrm{v} / \mathrm{v})$ to $50 \%$ TSC. After that 10 and $15 \mathrm{phr}$ of fruit extracts having $\mathrm{pH}$ value around 5.7 and viscosity $4.62 \mathrm{mPa} \cdot \mathrm{s}$ (matured and green Diospyros peregrina fruits were collected from Gazipur, Bangladesh) and a five phr n-butyl acrylate (n-BA) (purchased from Kanto Chem. Co. Inc., Japan) as radiation vulcanisation accelerator were added slowly to the NRL and mixed for an hour using a magnetic stirrer. The mixture was irradiated by Co- 60 gamma source at a dose rate of $313 \mathrm{Krad} \cdot \mathrm{h}^{-1}$ and was cast on raised rimmed glass plate
TABLE 1: Formulations and sample codes for the RVNRL films investigated in this study.

\begin{tabular}{lccc}
\hline $\begin{array}{l}\text { Sample codes used in } \\
\text { this study }\end{array}$ & $\begin{array}{c}\text { Latex } \\
(\mathrm{phr})\end{array}$ & $\begin{array}{c}\text { Fruit extract } \\
(\mathrm{phr})\end{array}$ & $\begin{array}{c}\mathrm{n}-\mathrm{BA} \\
(\mathrm{phr})\end{array}$ \\
\hline NR & 95 & 0 & 5 \\
NR-10 & 85 & 10 & 5 \\
NR-15 & 80 & 15 & 5 \\
\hline
\end{tabular}

moulds to obtain around $0.70 \mathrm{~mm}$ thick films with varying formulations (see Table 1). The RVNRL films were leached with distilled water for $24 \mathrm{~h}$ at room temperature and airdried until transparent films were achieved [31].

2.2. Morphological Characterisation. The surface morphology of the RVNRL films was characterised using an SEM (Philips XL30, FEI) at an accelerating voltage of $10 \mathrm{kV}$ and a working distance of $10 \mathrm{~mm}$. A sputtered platinum coating was used to avoid any charging effect on the film during the characterisation.

2.3. Surface Roughness Analysis. The surface roughness of RVNRL films was conducted on a Surftest (SV-600, Mitutoyo) using a diamond stylus tip ( $5 \mu \mathrm{m}$ tip radius, $0.05 \mu \mathrm{m}$, resolution, and $0.2 \mathrm{~mm} \mathrm{~s}^{-1}$ travel speed). Data were collected from $4.8 \mathrm{~mm}$ measurement distance and from at least ten different positions of each film.

2.4. Tensile Test. The tensile test (tensile strength, modulus at $500 \%$ elongation and elongation at break) of RVNRL films was conducted using dumbbell-shaped test specimens according to ISO 37-1977(E) method [32] on a universal tensile testing machine (Hounsfield-H50KS, UK).

2.5. Dynamic Mechanical Analysis (DMA). DMA were conducted using a Q800 from TA Instruments (USA) in multifrequency strain mode to investigate the tensile storage modulus $\left(E^{\prime}\right)$ and tan delta of RVNRL films with increasing temperature. The specimens were prepared by cutting strips from films with a width of $5 \mathrm{~mm}$ and length of $25 \mathrm{~mm}$ and heated from $-70^{\circ} \mathrm{C}$ to $60^{\circ} \mathrm{C}$ at rate of $10^{\circ} \mathrm{C} \mathrm{min}^{-1}$ using $15 \mathrm{~mm}$ gap distance, $0.1 \%$ strain, $0.01 \mathrm{~N}$ preload force, $125 \%$ force track, and $1 \mathrm{~Hz}$ frequency.

2.6. Differential Scanning Calorimetry (DSC) Analysis. The glass transition temperature $\left(T_{g}\right)$ of RVNRL films was investigated using a DSC instrument (Q2000, TA instruments, UK). The samples ( $\sim 7 \mathrm{mg}$ ) were heated from $-85^{\circ} \mathrm{C}$ to $50^{\circ} \mathrm{C}$ at a heating rate of $10^{\circ} \mathrm{C} \mathrm{min}^{-1}$ under nitrogen gas flow $\left(50 \mathrm{~mL} \mathrm{~min}^{-1}\right)$.

2.7. Thermogravimetric Analysis (TGA). TG analysis of RVNRL films was performed on a TA Q500 from $25^{\circ} \mathrm{C}$ to $600^{\circ} \mathrm{C}$ with a heating rate of $10^{\circ} \mathrm{C} \mathrm{min}^{-1}$ under $60 \mathrm{~mL} \mathrm{~min}^{-1}$ nitrogen gas flow. TA Universal analysis 2000 software was 
TABLE 2: Tensile properties of RVNRL films prepared from irradiated NR latex with varying proportion of fruit extracts.

\begin{tabular}{lccc}
\hline Samples & $\begin{array}{c}\text { Tensile strength }(\mathrm{MPa}) \\
( \pm \text { standard deviation })\end{array}$ & $\begin{array}{c}\text { Modulus at 500\% elongation }(\mathrm{MPa}) \\
( \pm \text { standard deviation })\end{array}$ & $\begin{array}{c}\text { Elongation at break (\%) } \\
( \pm \text { standard deviation })\end{array}$ \\
\hline NR & $28.85 \pm 0.58$ & $2.84 \pm 0.09$ & $1036 \pm 9$ \\
NR-10 & $31.56 \pm 0.50$ & $3.20 \pm 0.04$ & $1000 \pm 7$ \\
NR-15 & $32.68 \pm 0.43$ & $3.31 \pm 0.07$ & $996 \pm 11$ \\
\hline
\end{tabular}
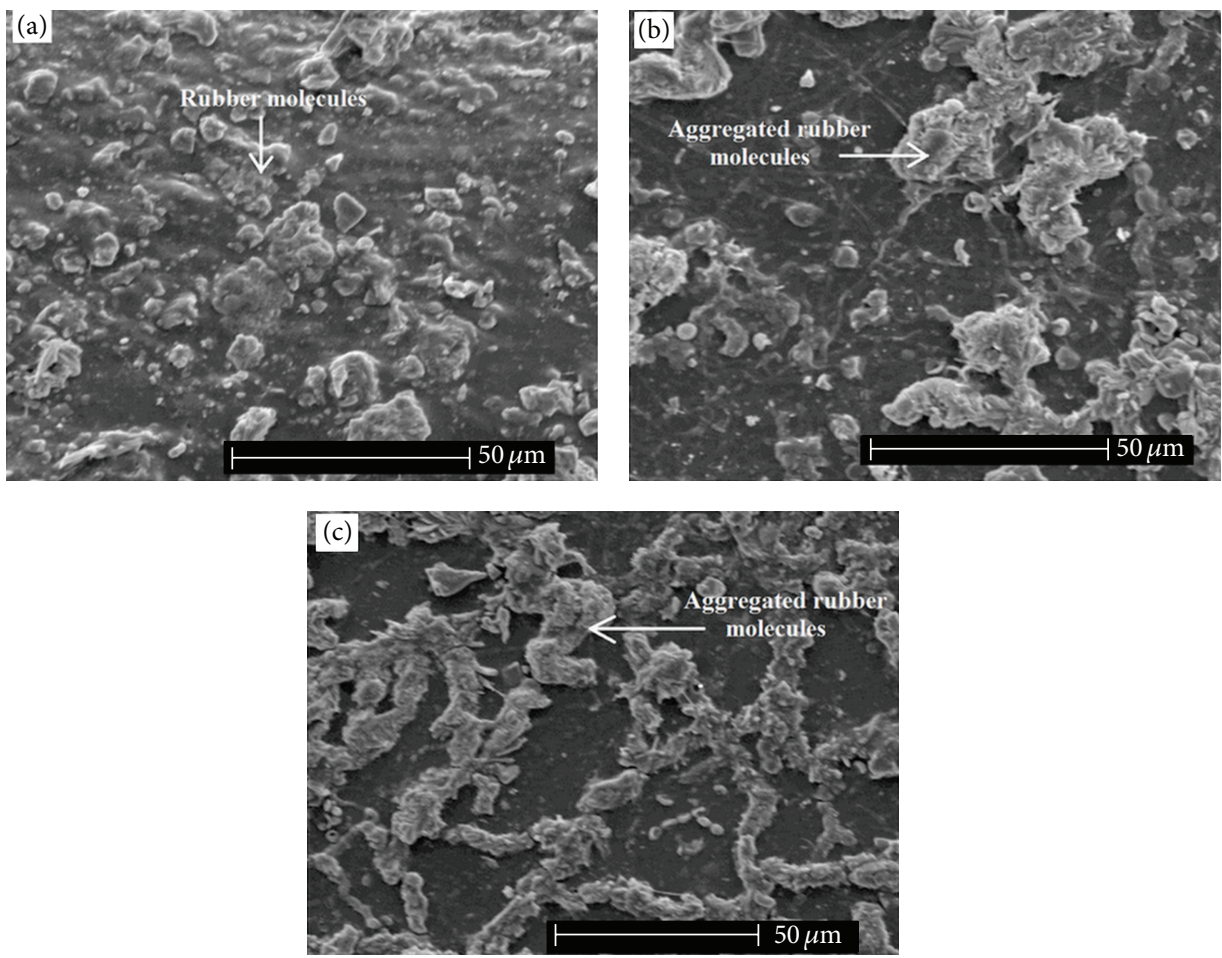

FIGURE 1: SEM images of radiation vulcanised natural rubber latex (RVNRL) films: (a) NR, (b) NR-10, and (c) NR-15.

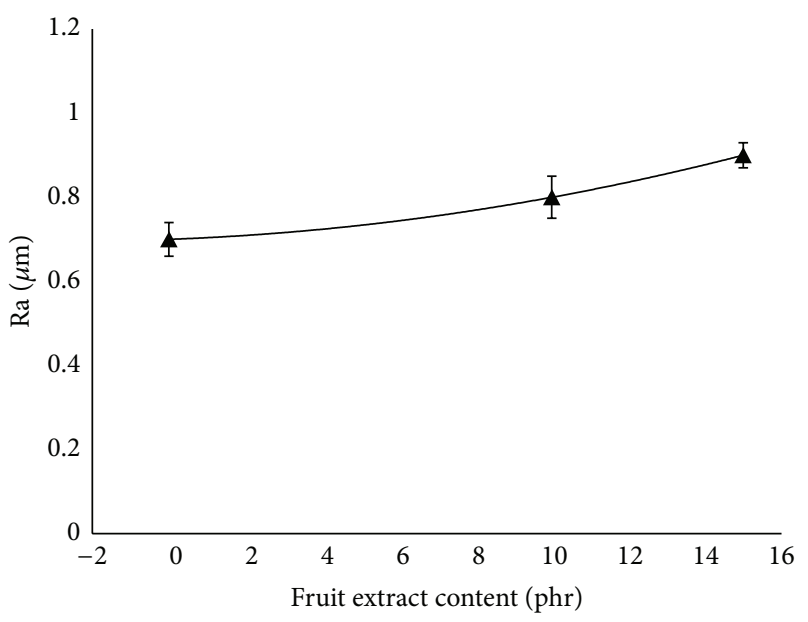

FIGURE 2: Relationship between the average surface roughness ( $\mathrm{Ra})$ and fruit extract content in RVNRL films.

used to calculate the weight loss (\%) and derivative weight loss with temperature from the TG scan.
2.8. X-Ray Diffraction (XRD) Analysis. The crystallinity of the RVNRL films was observed using a D500 diffractometer (SIEMENS) using a $\mathrm{Cu}-\mathrm{K} \alpha$ radiation source $(\lambda=0.154)$ at $30 \mathrm{kV}$ and $15 \mathrm{~mA}$ and the data obtained from $10^{\circ}$ to $40^{\circ} 2 \theta$ using a scan step time of $2 \mathrm{sec}$ and step size of $0.04^{\circ}$.

2.9. Swelling Properties. The swelling ratio (SR) of the rubber films was measured from the $10 \mathrm{~mm}$ round shape test specimens (at least five pieces) according to British standard (BS 1673: Part 4, 1953) by measuring the mass of the sample before and after immersing in toluene (purchased from Merck, Germany) for $72 \mathrm{~h}$ until equilibrium swelling at room temperature [32]:

$$
\mathrm{SR}=\frac{W_{s}-W_{d}}{W_{d}}
$$

where $W_{d}$ and $W_{s}$ are the weight of dry and swollen sample in toluene, respectively.

The swollen samples were then dried in an oven at $50^{\circ} \mathrm{C}$ for $48 \mathrm{~h}$ and then further vacuum dried at the same temperature for $24 \mathrm{~h}$ to remove the residual solvent. The gel 


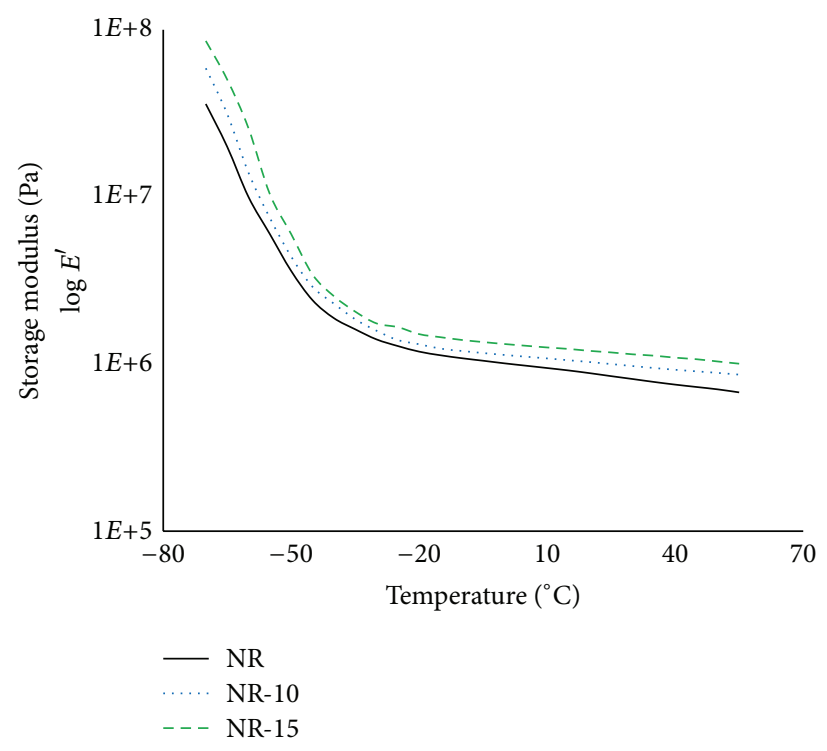

(a)

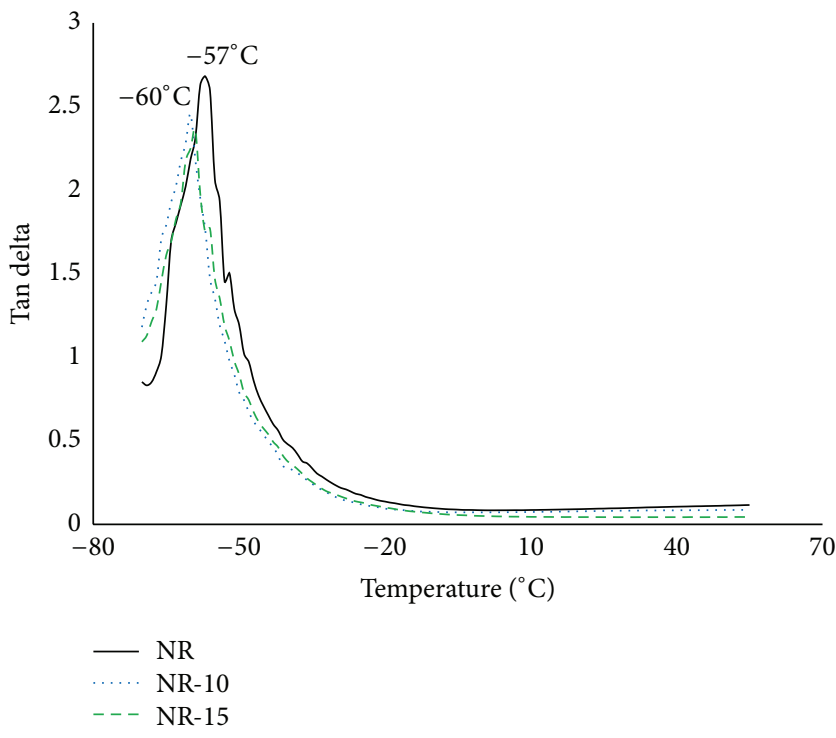

(b)

FIgURE 3: (a) Storage modulus and (b) tan delta curves of NR, NR-10, and NR-15 films obtained from DMA data.

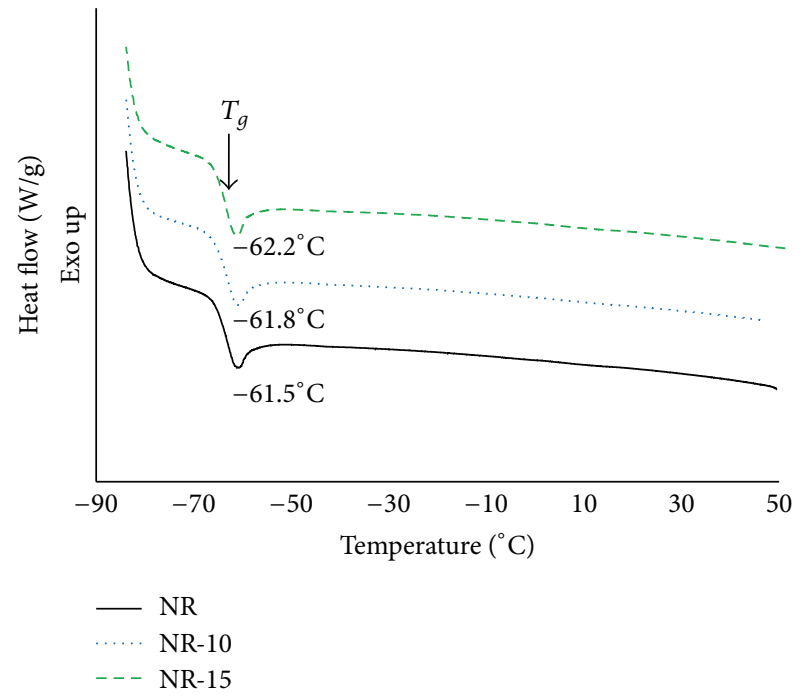

FIGURE 4: DSC thermogram of radiation vulcanised NR, NR-10, and NR-15 films.

content of the specimens was calculated using the following equation:

$$
\text { Gel content }=\frac{W_{d}-W_{d s}}{W_{d}}
$$

where $W_{d}$ and $W_{d s}$ are the weight of dry RVNRL films before and after being swollen in toluene, respectively.

2.10. Cross-Link Density Measurement. The physical crosslink density $\left(V_{e}\right)$ of the RVNRL films was calculated using the Flory-Rehner equation using the volume fraction $\left(V_{R}\right)$ of the swollen rubber network in the solvent at equilibrium state according to following equation [33]:

$$
\begin{gathered}
V_{e}=\frac{\left[\ln \left(1-V_{R}\right)+V_{R}+x_{1} V_{R}^{2}\right]}{V_{1}\left(V_{R}^{1 / 3}-V_{R} / 2\right)}, \\
V_{R}=\frac{W_{d} / \rho_{d}}{W_{d} / \rho_{d}+W_{\text {sol }} / \rho_{\text {sol }}},
\end{gathered}
$$

where $V_{1}$ and $X_{1}$ are the molar volume and interaction parameter of solvent (for toluene, $V_{1}=87.5 \mathrm{~mol} \cdot \mathrm{cm}^{-3}$ and $X_{1}$ $=0.39$ ) [3], $W_{d}$ and $\rho_{d}$ are the weight and density of dry rubber (for vulcanised rubber, $\rho_{d}=0.9203 \mathrm{~g} \cdot \mathrm{cm}^{-3}$ ) [15], and $W_{\text {sol }}$ and $\rho_{\text {sol }}$ are the weight and density of solvent (for toluene, $\rho_{\text {sol }}=$ $\left.0.865 \mathrm{~g} \cdot \mathrm{cm}^{-3}\right)$.

\section{Results and Discussion}

The use of aqueous extract of Diospyros peregrina as a natural antioxidant has already made them promising candidate to improve the mechanical properties of natural rubber after thermal aging because of their excellent antioxidant and gum-like properties. Here we investigated whether this natural gummy fruit extract can be used to improve the thermomechanical, crystallization, and swelling properties of RVNRL films by increasing their cross-link density.

3.1. Morphological and Surface Roughness Properties. The surface morphology of RVNRL films with varying fruit extract contents was analysed via SEM and is presented in Figure 1. Images obtained revealed the dispersion of rubber particulates within the film (Figure 1(a)). However, with the addition of fruit extracts the rubber particulates were observed to be aggregated as can be seen in Figures 


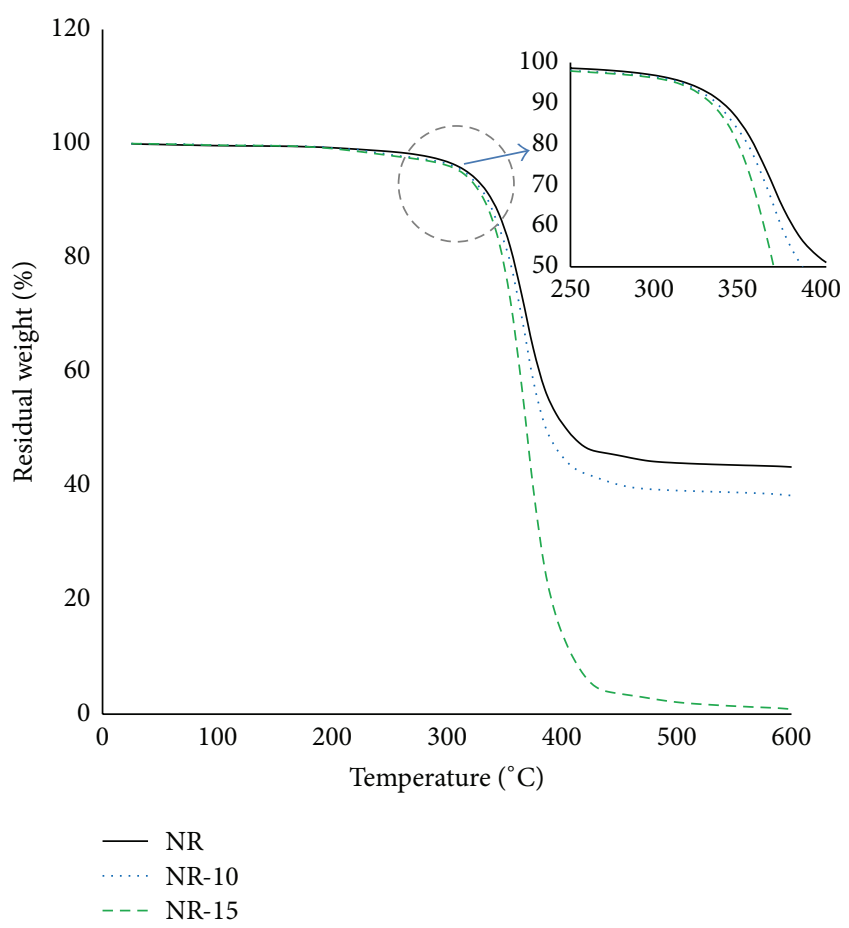

(a)

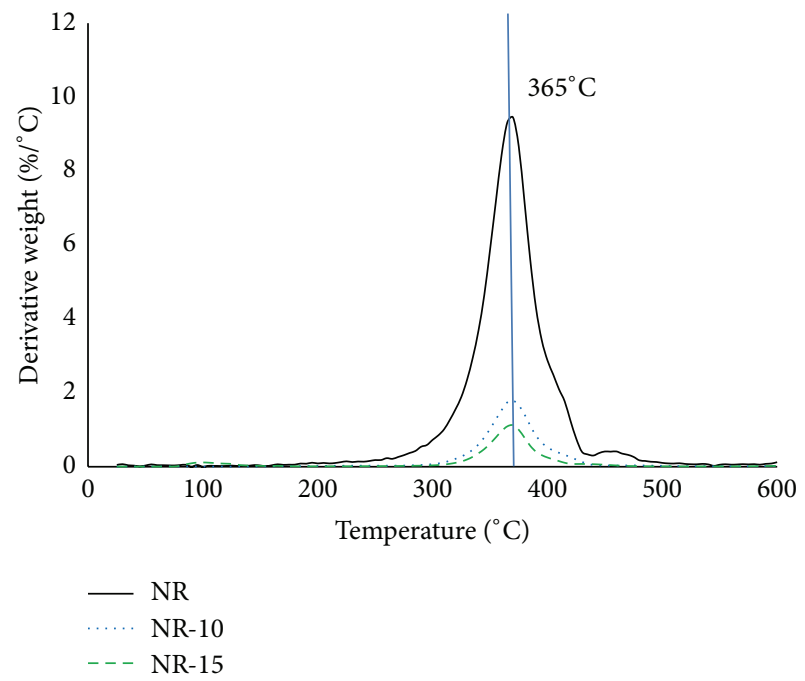

(b)

Figure 5: (a) TG and (b) DTG curves of radiation vulcanised NR, NR-10, and NR-15 films.

1(b) and 1(c). This was probably due to the presence of gum-like Diospyros peregrina fruit extracts which coagulated the rubber particulates during the blending and radiation vulcanisation processes.

The surface roughness profile of the RVNRL films with various fruit extract contents was measured and the relationship between the average surface roughness $(\mathrm{Ra})$ and the fruit extract contents in the RVNRL films is provided in Figure 2. The Ra value was observed increasing with the fruit extract content steadily from $\sim 0.7 \mu \mathrm{m}$ (NR) to $\sim 0.9 \mu \mathrm{m}$

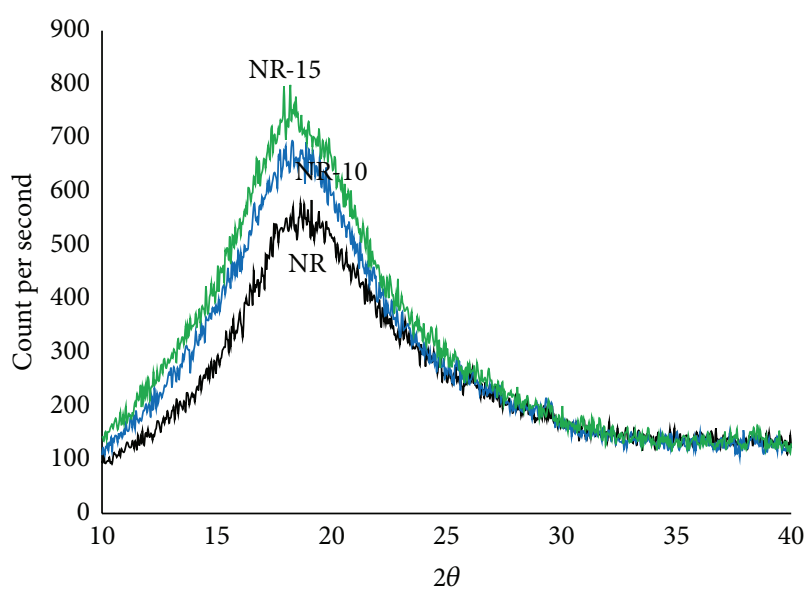

FIGURE 6: XRD traces of radiation vulcanised NR, NR-10, and NR-15 films.

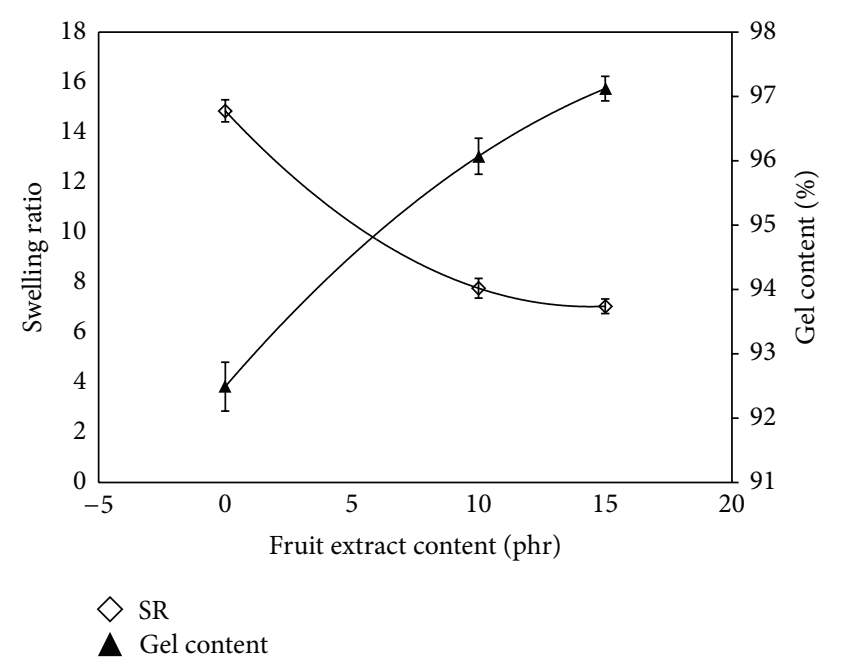

FIGURE 7: Swelling ratio and gel content of RVNRL films with various fruit extract contents.

(NR-15), which is in well agreement with the SEM images and again the aggregation of rubber particulates within the films was suggested.

3.2. Mechanical Properties. Tensile properties (tensile strength, modulus at $500 \%$ elongation and elongation at break) of the RVNRL films with varying fruit extract contents are tabulated in Table 2. Tensile strength and modulus at $500 \%$ elongation were found increasing with the addition of fruit extracts in the blend. For example, NR-15 film showed around $13.2 \%$ and $16.5 \%$ increase in tensile strength and modulus properties compared to NR film (tensile strength $\sim 28.85 \mathrm{MPa}$ and modulus $\sim 2.84 \mathrm{MPa}$ ). This was attributed to the influence of fruit extracts on increasing the cross-link density in RVNRL films during the radiation vulcanization [23] which was evaluated and this is discussed later in this paper. However, the elongation at break was observed decreasing with the addition of fruit extract, which was 


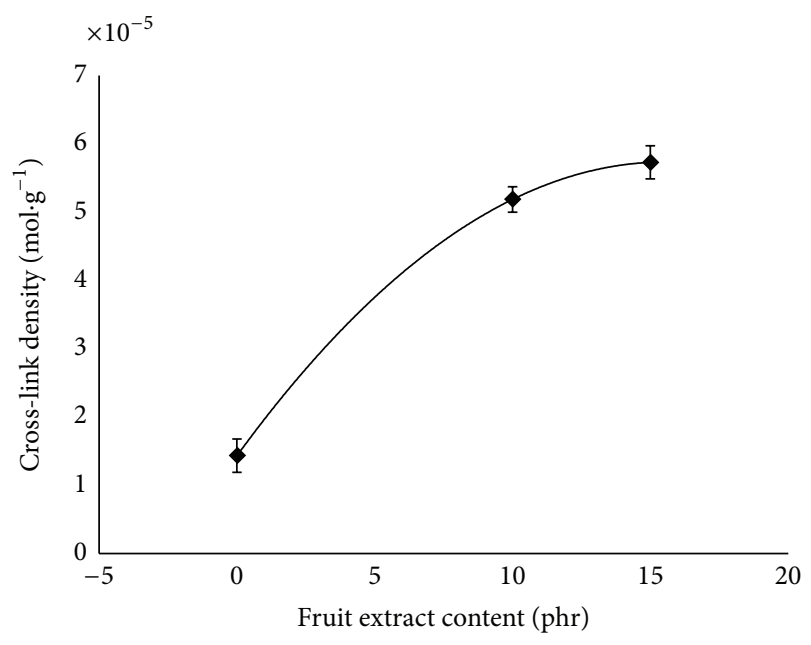

FIGURE 8: Cross-link density of RVNRL films with various fruit extract contents.

probably due to the stiffening effect of fruit extract on the irradiated rubber films.

3.3. Thermomechanical Properties. Figure 3(a) revealed the temperature dependency of storage modulus of RVNRL films with different fruit extract contents. The storage modulus of the RVNRL films showed an increasing trend with the addition of fruit extracts in the RVNRL films in the entire temperature region investigated in this study and this was again suggested to be due to the cross-linking effect of the fruit extract on the rubber hydrocarbon [34].

The variation of tan delta curves of NR, NR-10, and NR-15 films as a function of temperature is presented in Figure 3(b). It is observed from the tan delta curves that with the addition of fruit extracts the tan delta peaks ( $T_{g}$ values) of NR-10 and NR-15 films were seen to shift slightly to the left by $3^{\circ} \mathrm{C}$, that is, to the lower temperature regions as compared to the tan delta peak of NR (appeared at $-57^{\circ} \mathrm{C}$ ). The height of the tan delta peaks was also seen to decrease with the addition of fruit extracts in the RVNRL films compared to NR film. This was probably due to the presence of lower amount of rubber polymer in the NR-10 and NR-15 that were taking part in the thermal transition.

3.4. Thermal Properties. From the DSC analysis it can be seen that the glass transition temperature $\left(T_{g}\right)$ of $\mathrm{NR}$ appeared at around $-61.5^{\circ} \mathrm{C}$ (see Figure 4) which is in well agreement with the literature values $[4,35]$ and with the addition of fruit extracts in the blend $T_{g}$ values found to shift to the lower temperature region very slightly and this was in well agreement with the $T_{g}$ value measured via DMA using tan delta curves. Though a decrease in $T_{g}(P>0.05)$ and increase in mechanical and thermomechanical properties $(P<0.05)$ apparently showed a discrepancy when fruit extracts were added as a cross-linking agent within the natural rubber latex, however, this was presumably due to the plasticizing effect of the natural filler used in this study.
Thermogravimetry (TG) curves of the radiation vulcanised NR, NR-10, and NR-15 films are presented in Figure 5(a). The TG analysis revealed that all the RVNRL films were thermally stable up to $325^{\circ} \mathrm{C}$ ( $90 \%$ retention of residual weight), indicating that the processing temperature for these blends should be kept below $325^{\circ} \mathrm{C}$. However, at higher temperature (around $400^{\circ} \mathrm{C}$ ) the residual weight of the films was found to be decreased with the addition of fruit extracts which suggested the thermal instability of the additive used at the higher temperature.

The major thermal decomposition profiles of NR, NR10 , and NR-15 films were characterised from their derivative thermogravimetry (DTG) curves (presented in Figure 5(b)), which showed the maximum decomposition temperature $\left(T_{\max }\right)$ for all the RVNRL films at $365^{\circ} \mathrm{C}$. The thermal degradation of all the major functional groups in the RVNRL films occurred in the range $300 \sim 425^{\circ} \mathrm{C}$ through solid state transformations and loss of low molecular mass fragments.

3.5. Crystallisation Properties. The XRD traces of RVNRL films with varying filler contents are depicted in Figure 6. The diffraction patterns of all the RVNRL films revealed the natural rubber's characteristics peaks at around $19^{\circ}$ two theta [30]. An increase in the intensity of the XRD traces was observed with the addition of fruit extract, which was attributed to the induced crystallisation of the fruit extracts on the rubber polymer.

3.6. Swelling Properties and Cross-Link Density. The effect on the swelling ratio (SR) of radiation vulcanised rubber films with varying fruit extract contents obtained at $15 \mathrm{kGy}$ absorbed dose is showed in Figure 7. Swelling ratio decreased from 14.9 to 7.0 with the addition of $15 \mathrm{phr}$ fruit extracts to the blends. However, the gel content of the RVNRL films was seen to increase with the fruit extract contents in the RVNRL blends.

The physical cross-link density of the rubber hydrocarbon in RVNRL films with the addition of fruit extracts is presented in Figure 8. The cross-linking densities were observed increasing significantly to $5.2 \times 10^{-5} \mathrm{~mol} \cdot \mathrm{g}^{-1}$ in case of NR15 film compared to the control NR film $\left(1.5 \times 10^{-5} \mathrm{~mol} \cdot \mathrm{g}^{-1}\right)$. This was attributed to the effect of fruit extracts through the aggregation of rubber particulates within the vulcanised rubber films.

The RVNRL films produced in this study showed that the incorporation of Diospyros peregrina fruit extracts provides improvements in mechanical, thermomechanical, crystallisation, swelling, and cross-linking density properties of the radiation vulcanised rubber films when compared to the control NR film which could minimise the use of synthetic filler as well as toxic antioxidant in the natural rubber-based materials.

\section{Conclusion}

Aqueous extracts of Diospyros peregrina as natural crosslinking agent were successfully blended with rubber latex in various contents $(0,10$, and $15 \mathrm{phr})$ before being irradiated 
at $15 \mathrm{KGy}$ absorbed dose to obtain the RVNRL films. An aggregated morphology of the rubber particulates was seen with the incorporation of fruit extracts within the RVNRL films, which played an influential role in imparting some surface roughness on the films. The addition of fruit extracts within the rubber latex did not exhibit any significant change in their glass transition and thermal decomposition properties. However, an improvement in tensile strength, tensile modulus, and storage modulus properties of the rubber films demonstrated the cross-linking effect of the Diospyros peregrina fruit extracts in rubber particulates. The presence of $15 \mathrm{phr}$ fruit extract had a significant effect on increasing physical cross-linking density of the rubber films which influenced significantly decrease in swelling ratio and increase in the gel content and crystallisation properties of the RVNRL films.

\section{Acknowledgments}

The authors would like to thank the Atomic Energy Research Establishment (AERE), Savar, Bangladesh, for providing the natural rubber latex for this research work.

\section{References}

[1] N. K. On, A. A. Rashid, M. M. M. Nazlan, and H. Hamdan, "Thermal and mechanical behavior of natural rubber latexsilica aerogel film," Journal of Applied Polymer Science, vol. 124, no. 4, pp. 3108-3116, 2012.

[2] S. Ostad-Movahed, K. A. Yasin, A. Ansarifar, M. Song, and S. Hameed, "Comparing effects of silanized silica nanofiller on the crosslinking and mechanical properties of natural rubber and synthetic polyisoprene," Journal of Applied Polymer Science, vol. 109, no. 2, pp. 869-871, 2008.

[3] M. N. Qureshi and H. Qammar, "Mill processing and properties of rubber-clay nanocomposites," Materials Science and Engineering C, vol. 30, no. 4, pp. 590-596, 2010.

[4] S. S. Choi, S. H. Im, and C. Nah, "Influence of solvent swell and bound rubber on wax solubility of carbon black-reinforced NR composite," Journal of Applied Polymer Science, vol. 125, no. S1, pp. E342-E347, 2012.

[5] M. A. Atieh, N. Nazir, F. Yusof et al., "Radiation vulcanization of natural rubber latex loaded with carbon nanotubes," Fullerenes Nanotubes and Carbon Nanostructures, vol. 18, no. 1, pp. 56-71, 2010.

[6] S. Bhattacharyya, C. Sinturel, O. Bahloul, M. L. Saboungi, S. Thomas, and J. P. Salvetat, "Improving reinforcement of natural rubber by networking of activated carbon nanotubes," Carbon, vol. 46, no. 7, pp. 1037-1045, 2008.

[7] M. E. Haque, N. C. Dafader, F. Akhtar, and M. U. Ahmad, "Radiation dose required for the vulcanization of natural rubber latex," Radiation Physics and Chemistry, vol. 48, no. 4, pp. 505510, 1996.

[8] Y. Minoura and M. Asao, "Studies on the $\gamma$-irradiation of natural rubber latex," Journal of Applied Polymer Science, vol. 5, no. 14, pp. 233-239, 1961.

[9] L. V. Abad, L. S. Relleve, C. T. Aranilla, A. K. Aliganga, C. M. San Diego, and A. M. Dela Rosa, "Natural antioxidants for radiation vulcanization of natural rubber latex," Polymer Degradation and Stability, vol. 76, no. 2, pp. 275-279, 2002.
[10] A. Thiangchanya, K. Makuuchi, and F. Yoshii, "Degradability testing of radiation-vulcanized natural rubber latex films," Journal of Applied Polymer Science, vol. 54, no. 5, pp. 525-531, 1994.

[11] F. Yoshii, S. Kulatunge, and K. Makuuchi, "Improvement of ageing properties of rubber films prepared from radiationvulcanized natural rubber latex," Die Angewandte Makromolekulare Chemie, vol. 205, no. 1, pp. 107-115, 1993.

[12] K. Makuuchi, F. Yoshii, M. Kokuzawa, S. Kulatunge, and A. Thiangchanya, "Aging properties of radiation vulcanized NR latex film," Radiation Physics and Chemistry, vol. 42, no. 1-3, pp. 237-240, 1993.

[13] N. A. Abdelwahab, D. E. El-Nashar, and M. A. A. El-Ghaffar, "Polyfuran, polythiophene and their blend as novel antioxidants for styrene- butadiene rubber vulcanizates," Materials and Design, vol. 32, no. 1, pp. 238-245, 2011.

[14] M. N. Ismail, M. A. Abd El Ghaffar, K. A. Shaffei, and N. A. Mohamed, "Some novel polyamines as antioxidants for SBR vulcanizates," Polymer Degradation and Stability, vol. 63, no. 3, pp. 377-383, 1999.

[15] C. C. Ho and M. C. Khew, "Surface morphology of prevulcanized natural rubber latex films by atomic force microscopy: new insight into the prevulcanization mechanism," Langmuir, vol. 15, no. 19, pp. 6208-6219, 1999.

[16] B. Košíková, A. Gregorová, A. Osvald, and J. Krajčovičová, "Role of lignin filler in stabilization of natural rubber-based composites," Journal of Applied Polymer Science, vol. 103, no. 2, pp. 1226-1231, 2007.

[17] A. Gregorová, B. Košíková, and R. Moravčík, "Stabilization effect of lignin in natural rubber," Polymer Degradation and Stability, vol. 91, no. 2, pp. 229-233, 2006.

[18] F. H. A. Rodrigues, J. P. A. Feitosa, N. M. P. S. Ricardo, F. C. F. De França, and J. O. B. Carioca, "Antioxidant activity of Cashew Nut Shell Liquid (CNSL) derivatives on the thermal oxidation of synthetic cis-1,4-polyisoprene," Journal of the Brazilian Chemical Society, vol. 17, no. 2, pp. 265-271, 2006.

[19] J. S. Chauhan, M. Saraswat, and G. Kumari, "Structure of a new flavanone glycoside from Doiospyros peregrina roots," Indian Journal of Chemistry, vol. 21, pp. 169-170, 1982.

[20] R. N. Chopra and S. L. Nayar, Glossary of Indian Medicinal Plants, vol. 3, CSIR, New Delhi, India, 1992.

[21] N. Jain and R. Yadava, "Peregrinol, a lupane type triterpene from the fruits of Diospyros peregrina," Phytochemistry, vol. 35, no. 4, pp. 1070-1072, 1994.

[22] P. S. Misra, G. Misra, S. K. Nigam, and C. R. Mitra, "Constituents of diospyros peregrina fruit and seed," Phytochemistry, vol. 10, no. 4, pp. 904-905, 1971.

[23] K. M. Z. Hossain, A. M. S. Chowdhury, M. E. Haque, N. C. Dafader, and F. Akhtar, "Effect of natural antioxidant (diospyros peregrina) on the aging properties of radiation vulcanized ( $\gamma$ radiation) natural rubber latex film," Polymer-Plastics Technology and Engineering, vol. 49, no. 2, pp. 136-140, 2010.

[24] S. Dewanjee, A. K. Das, R. Sahu, and M. Gangopadhyay, "Antidiabetic activity of Diospyros peregrina fruit: effect on hyperglycemia, hyperlipidemia and augmented oxidative stress in experimental type 2 diabetes," Food and Chemical Toxicology, vol. 47, no. 10, pp. 2679-2685, 2009.

[25] S. Dewanjee, R. Sahu, V. Mandal, A. Maiti, and S. C. Mandal, "Antidiabetic and antioxidant activity of the methanol extract of Diospyros peregrina fruit on Type i diabetic rats," Pharmaceutical Biology, vol. 47, no. 12, pp. 1149-1153, 2009. 
[26] Encyclopedia of Chemical Technology, vol. 21, 4th edition.

[27] C. V. Chaudhari, Y. K. Bhardwaj, N. D. Patil, K. A. Dubey, V. Kumar, and S. Sabharwal, "Radiation-induced vulcanisation of natural rubber latex in presence of styrene-butadiene rubber latex," Radiation Physics and Chemistry, vol. 72, no. 5, pp. 613618, 2005.

[28] A. M. S. Chowdhury, M. A. Haque, K. M. Z. Hossain, M. E. Haque, N. C. Dafader, and F. Akhtar, "Study on the properties of radiation induced acrylamide grafted natural rubber latex film," Journal of Macromolecular Science A, vol. 48, no. 1, pp. 37-41, 2011.

[29] S. Merabet, F. Riahi, and A. Douibi, "The physical modification of a natural rubber-polypropylene thermoplastic elastomer blend by azobisformamide blowing agent," ISRN Polymer Science, vol. 2012, Article ID 168798, 6 pages, 2012.

[30] J. Johns and V. Rao, “Thermal stability, morphology, and X-ray diffraction studies of dynamically vulcanized natural rubber/chitosan blends," Journal of Materials Science, vol. 44, no. 15, pp. 4087-4094, 2009.

[31] S. S. Mahfuza, M. E. Haque, N. C. Dafader, F. Akhtar, and M. U. Ahmad, "Improvement of physical properties of radiation vulcanized natural rubber latex film," Journal of Macromolecular Science, vol. 33, no. 4, pp. 175-185, 1996.

[32] S. W. Karunaratne, "Standardization of radiation vulcanised natural rubber latex," in Proceedings of the International Symposium on Radiation Vulcanization of Natural Rubber Latex, JAERI-M 89-228, pp. 225-233, 1990.

[33] P. J. Flory and J. Rehner, "Statistical mechanics of cross-linked polymer networks II. Swelling," The Journal of Chemical Physics, vol. 11, no. 11, pp. 521-526, 1943.

[34] R. A. Stratton and J. D. Ferry, "Dynamic mechanical properties of natural rubber vulcanizates cross-linked by various agents," The Journal of Physical Chemistry, vol. 67, no. 12, pp. 2781-2785, 1963.

[35] D. R. Burfield and K. L. Lim, "Differential scanning calorimetry analysis of natural rubber and related polyisoprenes. Measurement of the glass transition temperature," Macromolecules, vol. 16, no. 7, pp. 1170-1175, 1983. 

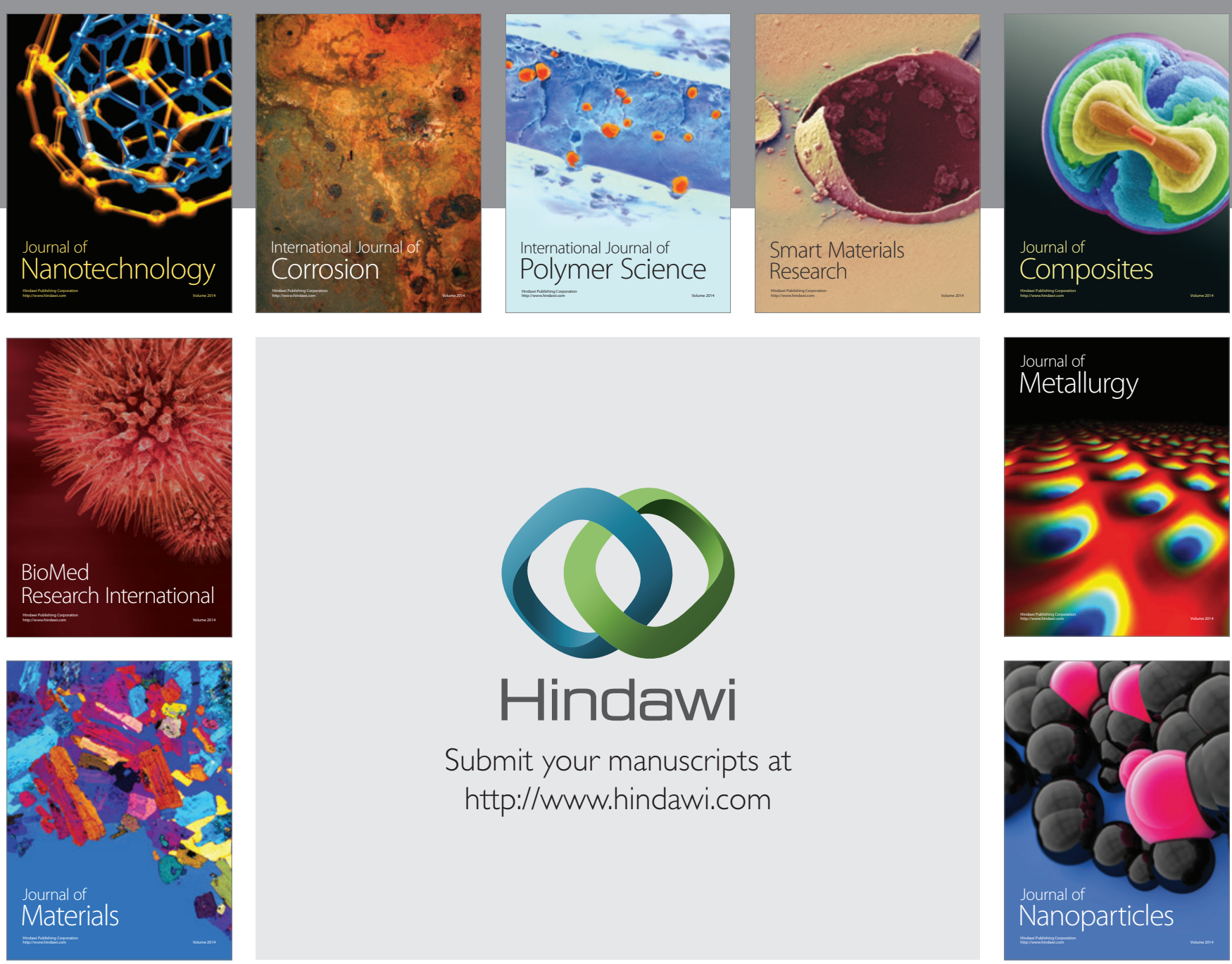

Submit your manuscripts at http://www.hindawi.com
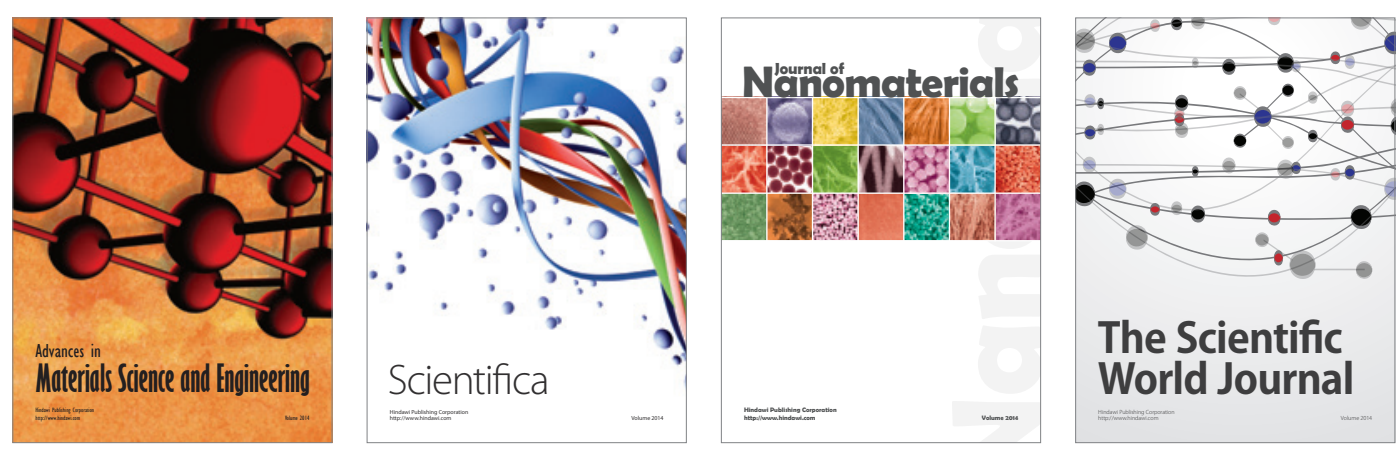

\section{The Scientific World Journal}
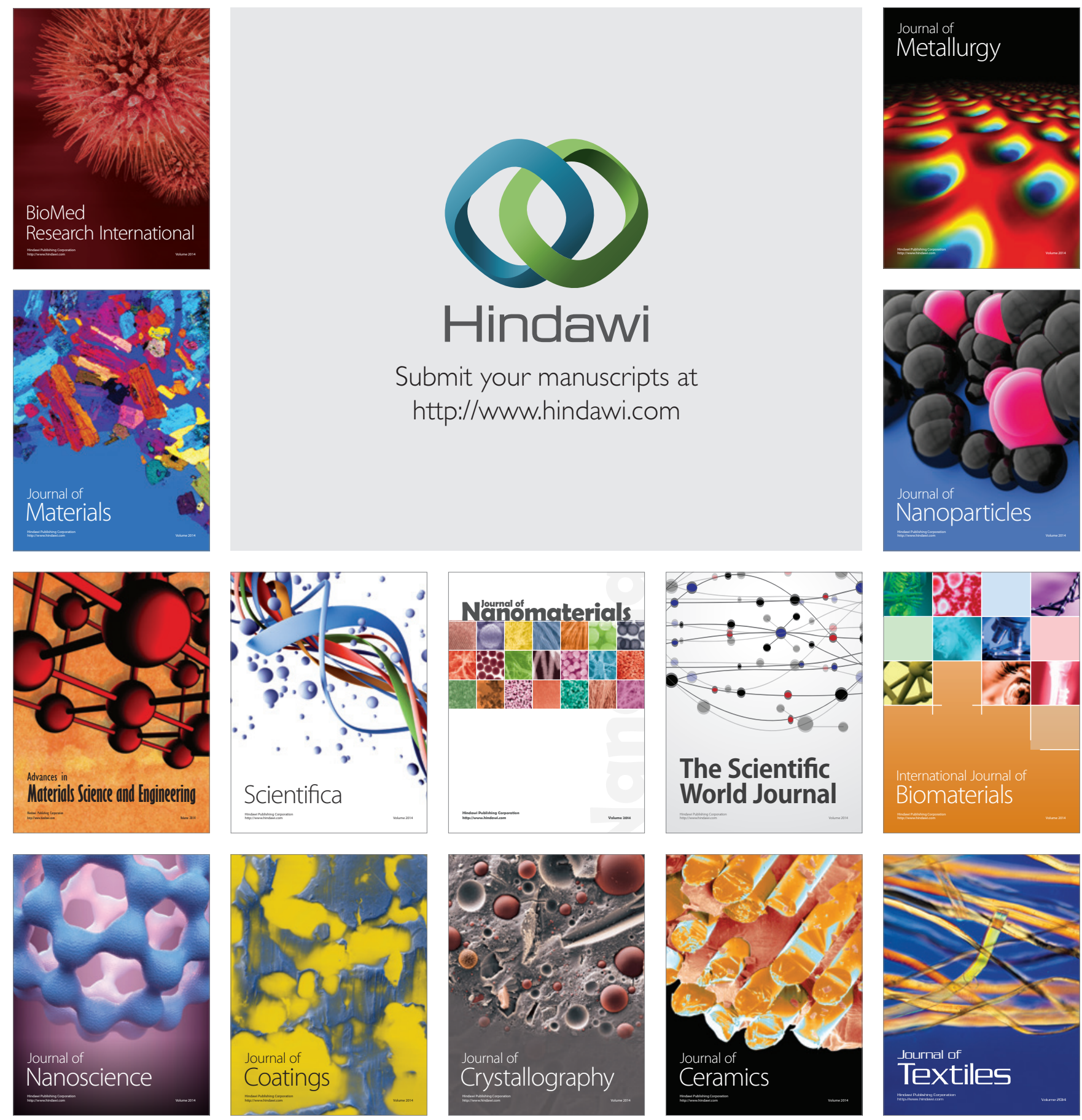